\title{
Psychometric Properties of the Coping Self-Efficacy Scale Among HIV-Infected Iranian Patients
}

\author{
Maryam Mahmoudi ${ }^{1}$; Davoud Shojaezadeh ${ }^{1, ;}$; Tahereh Dehdari ${ }^{2}$; Ebrahim Hajizadeh ${ }^{3}$; \\ Mohammad Hossein Taghdisi ${ }^{2,4} ;$ Ladan Abbasian $^{5} ;$ Mahdiyeh Roohi $^{6}$ \\ ${ }^{1}$ Department of Health Education and Promotion, School of Public Health, International Campus of Tehran University of Medical Sciences, Tehran, IR Iran \\ ${ }_{3}^{2}$ Department of Health Education and Health Promotion, School of Public Health, Iran University of Medical Sciences, Tehran, IR Iran \\ ${ }_{4}^{3}$ Department of Biostatistics, Faculty of Medical Sciences, TarbiatModares University, Tehran, IR Iran \\ ${ }^{4}$ Research Council Member of Center for Community Based Participatory Research Tehran, IR Iran \\ ${ }_{5}$ Research Council Member of Center for Community Based Participatory Research Tehran, IR Iran \\ Iranian Research Center of HIV| AIDS, Iranian Institute for Reduction of High- Risk Behavio
${ }_{\text {Department }}$ of Clinical Psychology, Islamic Azad University, Saveh Branch, Saveh, IR Iran \\ * ${ }^{*}$ Corresponding Author: Davoud Shojaezadeh, Department of Health Education and Promotion, School of Public Health, International Campus of Tehran University of Medical Sci- \\ ences, Tehran, IR Iran. Tel: +98-2188989128, Fax: +98-2188989129, E-mail: Shojaei@tums.ac.ir
}

Received: November 3, 2014; Revised: December 5, 2014; Accepted: December 31, 2014

\begin{abstract}
Background: Self-efficacy is an important predicator of coping with stress.
Objectives: This study aimed to determine the psychometric characteristics of the coping self-efficacy (CSE) scale among HIV-infected Iranian patients.

Patients and Methods: Psychometric properties of the CSE scale were examined by using a cross-sectional study design. One hundred and twenty HIV-infected Iranian patients that had been referred to the Counseling of Behavioral Diseases Center at Imam Khomeini Hospital in Tehran, Iran in 2014 were selected through simple random sampling method. To determine the Content Validity Index (CVI) and the content validity ratio (CVR), a panel of experts $(n=20)$ reviewed items of CSE scale. Reliability was estimated through the internal consistency $(\mathrm{n}=30)$ and the conformity factor analysis was performed.

Results: Iranian version of the CSE scale contained 16 items, including 7 items on the "use of problem-focused coping" method, 5 items on "stopping unpleasant emotions and thoughts", and 4 items on "getting support from friends and family". CVI and CVR scores were $0.79,0.42$ and more, respectively. Internal consistencies (range, 0.64 to 0.84 ) of 3 subscales were acceptable. Confirmatory factor analysis showed that comparative indices of the model, including CFI, IFI, GFI, RMSEA, and Chi-square ( $\chi 2 / \mathrm{df}$ ) were 0.96, 0.95, 0.84, 0.83, and 1.82, respectively, which indicated a good fit for the data.

Conclusions: The Iranian version of the CSE scale is a valid instrument to measure the coping self-efficacy among people living with HIV in research and community settings in Iran.
\end{abstract}

Keywords:Self-efficacy; HIV; Psychometric; Iran

\section{Background}

People living with HIV/AIDS experience more stress in their lives compared to those living with other diseases (1). HIV-related stressors may lead to the use of maladaptive coping strategies such as avoidance and denial of the disease (2). Using adaptive strategies will help HIV-infected individuals maintain their psychological and physical health. The ability to cope successfully with a chronic illness such as AIDS is influenced by a number of social and psychological factors (3). One of the important psychological factors is coping self-efficacy (CSE). Patients having high CSE are able to engage more in adaptive coping behaviors. They also have lower depression rates and higher disclosure (4). CSE is rooted in the concept that people truly need to believe they are capable of engaging in a coping behavior in order to effectively participate in adaptive coping behaviors (5). CSE is related to stress and coping theory (6) that focuses on managing behavioral and cognitive responses to stressful situations (7). Belief about self-efficacy is part of a secondary evaluation of stress and coping theory, which also addresses the judgment of controllability of stress through coping (8). CSE would be expected to influence outcomes of interventions designed to enhance coping of personal efficacy and reduction of one's psychological distress and improvement of well-being (5). To measure the exact level of CSE in patients using psychometric measures is essential. To the best of our knowledge, there has not been any scale available in Iran to assess the CSE level among people living with HIV/AIDS. The 26-item CSE scale developed was a valid instrument to measure the perceived self-efficacy to cope with life challenges or threats (9).

\section{Objectives}

This study aimed to measure psychometric characteristics of CSE scale among those people living with HIV in Tehran, Iran, during June to September 2014.

Copyright ( 2015, Iranian Red Crescent Medical Journal. This is an open-access article distributed under the terms of the Creative Commons Attribution-NonCommercial 4.0 International License (http://creativecommons.org/licenses/by-nc/4.0/) which permits copy and redistribute the material just in noncommercial usages, provided the original work is properly cited. 


\section{Materials and Methods}

\subsection{Design and Procedure}

Psychometric properties of the CSE scale were examined using a cross-sectional study design. Steps to examine the psychometric characteristics of CSE scale are presented in the following sections.

\subsubsection{Translation of English Version of CSE Scale to Farsi}

The original version of CSE-26 was translated from English to Farsi. Backward translation was reviewed by an independent group of experienced researchers and linguistics in order to achieve a reliable Farsi version. The translation group consisted of 4 researchers and 2 translators. Translators carefully reviewed the document and then provided translated English version of CSE scale as a complete representation in terms of phrasing and content with respect to Iranian culture.

\subsubsection{Content Validity}

Content validity of this instrument was evaluated qualitatively and quantitatively. The content validity ratio(CVR) and the content validity index (CVI) of each item were calculated based on the opinions of 20 experts. We asked all of the experts on the panel to judge the rate of necessity of each item; therefore, those items with a CVR score of 0.42 and more were approved and those with CVI score of 0.79 and above were considered satisfactory $(10,11)$.

\subsubsection{Face Validity}

A group of HIV-infected patients $(n=20)$ were asked to comment on the clarity, simplicity, and legibility of the items of CSE scale (face validity). Following their comments, less cleared items and or vague questions were revised and some minor errors were corrected as well.

\subsubsection{Construct Validity}

The construct validity of the 16-item instrument scale was determined by confirmatory factor analysis (CFA). To evaluate the model fitness, 120 eligible HIV-infected patients that had been referred to the counseling of behavioral diseases center at the state hospital of Imam Khomeini in Tehran, Iran in 2014 were selected through simple random sampling method. It should be noted that approximately 7 cases per each item of CES-16 were selected (12). The selection criteria for this study were as follows: 1) patients' agreement to participate, 2) male and female patients with medically documented HIV infection, 3 ) patients $\geq 18$ years, 4 ) ability to read and write in Farsi. One of the research faculty at the clinic was able to identify 135 patients who met the eligibility criteria on the day of their appointments; however, only 120 of those eligible patients willingly accepted to participate in this study (exclusion $=15$ ). All participants were in- formed about the study objectives and; therefore, a written consent was obtained from all participants. Rights of the participants were completely respected and they were ensured of anonymity of their responses. This study was approved on June 11, 2014 by the Ethics Committee of Tehran University of Medical Sciences (No. 93-130-446). Participants were asked to answer all the questions such as 'When you think things aren't going well for you,' or 'when you feel you're having problems,' and 'how confident you are that you can do the following' in the instrument. Then, the patients were asked to rate on an 11-point scale with three Anchor points on the scale were zero ('cannot do at all'), 5 ('moderately certain can do') and 10 ('certain can do'). All various fit indicated relative chi-square $(\chi 2 / \mathrm{df})$, comparative fit index (CFI), incremental fit index (IFI), normed fit index (NFI), non-normed fit index (NNFI), root mean square error of approximation (RMSEA), and standardized root mean square residual (SRMR) (13). Relative Chi-square was obtained by dividing the chi-square by degrees of freedom where the recommended reference value should be less than 3 to be an acceptable fitness for the model (12). The values of CFI, IFI, NFI, and NNFI could range between 0 and 1 where values closer to 1 are indicative of data fitness (14). An RMSEA range from 0.08 to 0.10 shows a mediocre fit and values below 0.8 indicate a good fit (15). The acceptable value for SRMR is below 0.10 where values less than 0.8 indicate an adequate fit and values less than 0.5 indicate good fit $(16,17)$.

\subsubsection{Reliability}

Internal consistency of the CSE scale was assessed using Cronbach $\alpha$ coefficient. In addition, a sub-sample of patients $(\mathrm{n}=30)$ completed the instrument. $\alpha$ values of equal or greater than 0.70 was considered satisfactory (18).

\subsection{Statistical Analysis}

Statistical analysis such as mean and standard deviations were performed using SPSS (version 17.0, SPSS, Inc., Chicago, IL, USA) and CFA was performed using the LISREL 8.80 for Windows (19).

\section{Results}

\subsection{Demographic Variables}

The mean age of the participants in the CFA was 34.74 $y(S D= \pm 7.14)$. Other demographic characteristics of the participants are shown in Table 1.

\subsection{Content Validity}

According to the panel of experts and their feedback, CVI and CVR were calculated for each item. The CVI and CVR scores of items were $0.79,0.42$ and higher, respectively. The CVR of 4 items were less than 0.42 , so those 
Mahmoudi M et al.

were removed including two items in the first subscales, one item in the second and one item in the third one. Due to similarity of the concept among 6 items, they were merged together in their subscales. The prefinal version of the instrument contained 16 items, including 7 items on the use of the problem-focused coping, 5 items on the stopping unpleasant emotions and thoughts, and 4 items on getting support from friends and family among subscales (Table 2).

\subsection{Confirmatory Factor Analysis}

All variables were checked to be normally distributed before implementation of CFA. The 16-item instrument was examined for CFA. The relative chi-square $(\chi 2 / \mathrm{df})$ was 1.82 , indicating the fitness of the model $(\mathrm{P}<0.001)$. Comparative indices of the model, including CFI, IFI, NFI, and NNFI were 0.96, 0.95, 0.92, and 0.94, respectively, indicating the goodness of fit for the data. The RMSEA of the model was 0.083 (90\% CI, 0.064-0.10). SRMR was less than 0.08 (0.06) confirming an acceptable fit for the model. The result of confirmatory factor analysis is shown in Figure 1. Table 3 demonstrates score distribution, ceiling, and floor effect of results.
Table 1. Demographic Characteristics of the Participants in the Factor Analysis

\begin{tabular}{lc}
\hline Variable & Frequency \\
\hline Age, $\mathbf{y}$ & $34.74 \pm 7.14$ \\
\hline Sex & $72(60)$ \\
\hline Male & $40(48)$ \\
\hline Female & \\
\hline Marital status & $50(41.7)$ \\
\hline Single & $52(43.3)$ \\
\hline Married & $11(9.2)$ \\
\hline Divorced & $7(15.4)$ \\
\hline Widow & $1(0.8)$ \\
\hline Education level & $91(75.8)$ \\
\hline Illiterate & $28(23.3)$ \\
\hline$\leq 12^{\text {th }}$ grade & \\
\hline$>12^{\text {th }}$ grade & $8(30.8)$ \\
\hline Occupation status & $17(14.2)$ \\
\hline Housekeeper & $63(52.5)$ \\
\hline Employee & \\
\hline Self-employed & \\
\hline a Data are presented as No. (\%) or Mean \pm SD. & \\
\hline
\end{tabular}

Table 2. Cronbach $\alpha$ for Items and Subscales of Iranian Coping Self-efficacy

\begin{tabular}{llr}
\hline Items/Subscales & No. of items and Scale range & Mean \pm SD Cronbach $\alpha$ \\
\hline Use problem-focused coping & $\begin{array}{l}\text { 7 items on a 11-point scale from } 0 \\
=\text { ('cannot do at all) degree to } 10=\end{array}$ & 0.84
\end{tabular}
(certain)

I break my problems down into smaller parts first and then think about each part of the problem at a time.

I sort out what can be changed, and what cannot be changed.

$5.88 \pm 2.57$

I leave my options open when things get stressful and find differ-

ent solutions for my most challenging problems.

I resist the impulse to act hastily when I am under pressure.

$5.76 \pm 2.76$

When confronting a problem, I make an action plan first; then try

$4.56 \pm 3.10$

to find different solution for my problem if my first solution does

$6.33 \pm 2.61$

not work.

Make myself believe that I am capable of solving my problems.

$6.91 \pm 2.92$

I develop new hobbies or recreations.

Stop unpleasant emotions and thoughts

$6.50 \pm 3.31$

5 items on a 11 point scale $0=($ "cannot do at all $)$ degree to $10=($ certain $)$

I always try to avoid unpleasant thoughts as they, more than likely, make me feel sad and lonely.

I look for something positive for myself in a negative situation.

I try to pray to remain calm when I am under pressure.

I take my mind off unpleasant thoughts.

I try to visualize a pleasant activity or place in unpleasant situation.

Support from friends and family

4 items on a 11 point scale from 0

$=($ 'cannot do at all $)$ degree to $10=$ (certain)

I get emotional support from community organizations or re-

sources.

I get friends to help me with the things I need.

I get emotional support from friends and family.

Do something positive for myself when I feel discouraged. 
Figure 1. Three-Factor Model for the Instrument Obtained From Confirmatory Factory Analysis $(\mathrm{n}=120)$

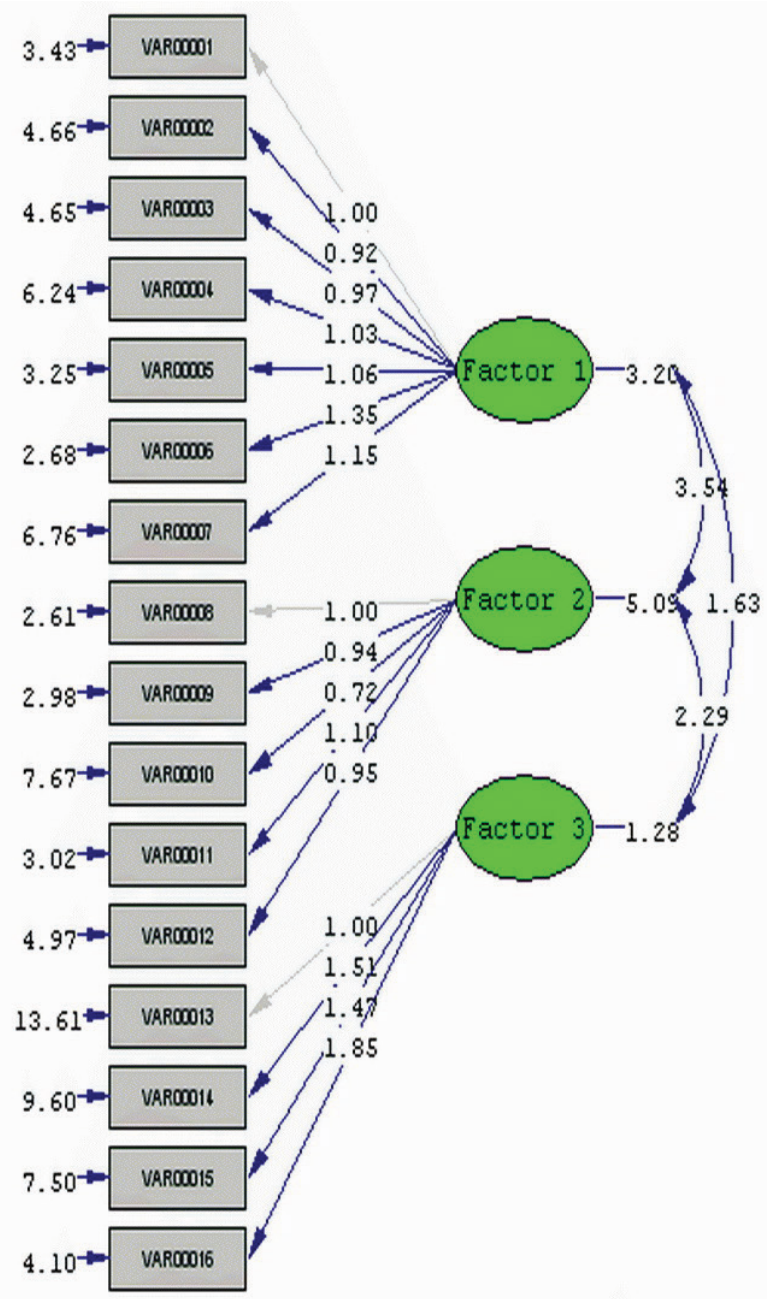

Chi-Square $=184.69, \mathrm{df}=101, \mathrm{P}$-value $=0.00000, \mathrm{RMSEA}=0.083$

Factor 1 = Use problem-focused coping, Factor 2 = Stop unpleasant emotions and thoughts, Factor $3=$ Get support from friends and family.

Table 3. Score Distribution, Ceiling, and Floor Effect of the 16-CSE-S ${ }^{\text {a }}$

\begin{tabular}{lcccc}
\hline & $\begin{array}{c}\text { Number } \\
\text { of Items }\end{array}$ & Mean \pm SD & $\begin{array}{c}\text { Ceiling } \\
\text { Effect }\end{array}$ & $\begin{array}{c}\text { Floor } \\
\text { Effect }\end{array}$ \\
\hline Factor 1 & 7 & $42.10 \pm 14.4$ & 44.2 & 6.7 \\
\hline Factor 2 & 5 & $28.7 \pm 11.60$ & 37.5 & 9.2 \\
\hline Factor 3 & 4 & $21.20 \pm 9.42$ & 35 & 13.3 \\
\hline
\end{tabular}

\subsection{Reliability}

Cronbach $\alpha$ of 3 subscales was acceptable (range, 0.730.84). Table 2 presents Cronbach $\alpha$ coefficients of subscales.

\section{Discussion}

The present study demonstrated different stages of psychometric characteristics of CSE scale among people living with HIV in Iran. The findings showed that modified CSE instrument with 16 items and 3 factors was a valid and reliable tool to detect HIV coping self-efficacy among Iranian patients. Confirmatory factor analysis showed a good fit for the data. The only development of Iranian version of coping self-efficacy scale has been conducted among type 2 diabetic patients in Tol et al. study (20). Content validity, reliability, and cultural equivalency were evaluated by qualitative and quantitative study. Final version of the construct validity and factor analysis were tested and as a result, 2 items were deleted and 1 factor was also extracted as a self-efficacy on diabetic problem solving. However, the internal consistencies were lower than the present study but they were approved by a psychometric analysis, which was consistent with this study. It needs to be taken into consideration that diabetic patients' setting is completely different from that of people living with HIV in Iran, since HIV related stresses are much more complicated. Despite the lack of validating study for coping self-efficacy scale, the general self-efficacy has been developed in several studies, where it typically yielded internal consistencies between $\alpha=0.75$ and $\alpha=0.90$ (21). Previous studies reported excellent reliability and validity as a measure of self-efficacy beliefs to cope with the consequences of arthritis disease $(22,23)$. The results showed that CVI and CVR of all scaled items were satisfactory. The CVR and CVI values for 20 expert panels were 0.42 and 0.80 (10-11). Rubio et al. suggested that the experts' opinions are the best methods for evaluating the content validity (24). However the result of the present study was not exactly supported in content validity of the original CES and because of experts' opinions during the quantitative content validity process, 4 items were deleted and 6 items of CES-26 merged together. For example, 'Leave options open when things get stressful' was merged with 'Find solution to your most difficult problem' in one sentence as, 'I leave my options open when things get stressful, so hopefully I can find different solutions to my most challenging problems.' The results indicated that Cronbach $\alpha$ for the 16 items and 3 subscales of instrument were satisfactory. In line with Ludane, Cronbach $\alpha$ of CSE sub-scales ranged from 0.63 to 0.90 (25).

This study was the first research study of its kind (strong point of the study), which assessed validity of CSE scale among people living with HIV in Iran in which practitioners could use validated scale to determine CSE among those patients with adaptive coping behavior in the Iranian context. Limitation of this study was that the sample data was only collected of those HIV/AIDS patients at the Counseling of Behavioral Diseases Center affiliated to Tehran University of Medical Sciences in Tehran. Also considering the fact that this clinic was located in central 
Tehran, the homogeneity of samples may limit the extent to which the findings can be generalized to other areas of the city. More researches and studies should be done in order to assess the validity of this scale among other racial or ethnic groups and other geographic areas in Tehran or other cities in Iran. This study confirmed that the 16-item CSE scale was a valid and reliable tool to use for the population infected with HIV in Iran. This instrument can help educators and psychologists to measure the HIV coping self-efficacy in the research and community settings in Iran.

\section{Acknowledgements}

This study was part of a PhD thesis and was financially supported by the International Campus of Tehran University of Medical Sciences, grant number 93-130-446. The authors wish to thank the HIV/AIDS patients as well as the Iranian Research Center for HIV/AIDS (IRCHA) personnel that are affiliated to Tehran University of Medical Sciences for their assistance and cooperation. The authors declared that they had no conflict of interests.

\section{Authors' Contributions}

Study concept and design: Davoud Shojaezadeh; Acquisition of data: Maryam Mahmoudi; Analysis and interpretation of data: Mohammad Hossein Taghdisi and Mahdiyeh Roohi; Drafting of the manuscript: Maryam Mahmoudi; Critical revision of the manuscript for important intellectual content: Tahereh Dehdari; Statistical analysis: Ebrahim Hajizadeh administrative technical, and material support: Ladan Abbasian; and Study supervision: Tahereh Dehdari.

\section{References}

1. Siegel K, Schrimshaw EW. Perceiving benefits in adversity: stressrelated growth in women living with HIV/AIDS. Soc Sci Med. 2000;51(10):1543-54.

2. Moneyham L, Hennessy M, Sowell R, Demi A, Seals B, Mizuno Y. The effectiveness of coping strategies used by HIV-seropositive women. Res Nurs Health. 1998;21(4):351-62.

3. Lazarus RS. From psychological stress to the emotions: a history of changing outlooks. Annu Rev Psychol. 1993;44:1-21.

4. Rodkjaer L, Chesney MA, Lomborg K, Ostergaard L, Laursen T, Sodemann M. HIV-infected individuals with high coping self- efficacy are less likely to report depressive symptoms: a crosssectional study from Denmark. Int J Infect Dis. 2014;22:67-72.

5. Chesney MA, Chambers DB, Taylor JM, Johnson LM, Folkman S. Coping effectiveness training for men living with HIV: results from a randomized clinical trial testing a group-based intervention. Psychosom Med.2003;65(6):1038-46.

6. Lazarus RS, Folkman S. Stress, Appraisal, and Coping.; 1984.

7. Folkman S. Positive psychological states and coping with severe stress. Soc Sci Med.1997;45(8):1207-21.

8. DiClemente CC, Fairhurst SK, Piotrowski NA. Self-Efficacy and Addictive Behaviors. Springer. 1995:109-41.

9. Chesney MA, Neilands TB, Chambers DB, Taylor JM, Folkman S. A validity and reliability study of the coping self-efficacy scale. $\mathrm{Br} J$ Health Psychol. 2006;11(Pt 3):421-37.

10. Lawshe $\mathrm{CH}$. A quantitative approach to content validity1. Pers Psychol.1975;28(4):563-75.

11. Polit DF, Beck CT. Essentials of nursing research.: Lippincott Williams \& Wilkins; 2013.

12. Munro BH. Statistical methods for health care research.: Lippincott Williams \& Wilkins; 2005.

13. Mueller RO. Basic principles of structural equation modeling: An introduction to LISREL and EQS.: Springer; 1996.

14. Kline RB. Principles and practice of structural equation modeling.: Guilford press; 2011.

15. MacCallum RC, Browne MW, Sugawara HM. Power analysis and determination of sample size for covariance structure modeling. Psychol Methods. 1996;1(2):130.

16. Bollen KA, Long JS. Testing structural equation models.: SAGE Publications; 1993.

17. Hu LT, Bentler PM. Cutoff criteria for fit indexes in covariance structure analysis: Conventional criteria versus new alternatives. Struct Equ Modeling Multidiscip J.1999;6(1):1-55.

18. Waltz CF, Strickland O, Lenz E. R. . Measurement in nursing and health research. 4th ed: Springer Publishing Company; 2010.

19. Joreskog KG, Sorbom D. LISREL 8.8 for Windows [Computer software].Lincolnwood, IL: Scientific Software International; 2006.

20. Tol A, Mohebbi B, Hossaini M, Majlessi F. Developing a Valid and Reliable Coping Self-Efficacy Scale (CSES) among Patients with Type 2 Diabetes: Iranian Version. Open J Endocr Metab Dis. 2014;4:45-51.

21. Schwarzer R, Jerusalem M. Generalized self-efficacy scale A user's portfolio. Causal and control beliefs. Meas health psychol. 1995;1:35-7.

22. Barlow JH, Williams B, Wright CC. The reliability and validity of the arthritis self-efficacy scale in a UK context. Psychol Health Med. 1997;2(1):3-17.

23. Hewlett S, Cockshott Z, Kirwan J, Barrett J, Stamp J, Haslock I. Development and validation of a self-efficacy scale for use in British patients with rheumatoid arthritis (RASE). Rheumatology (Oxford). 2001;40(11):1221-30.

24. Rubio DM, Berg-Weger M, Tebb SS, Lee ES, Rauch S. Objectifying content validity: Conducting a content validity study in social work research. Soc Work Res. 2003;27(2):94-104.

25. Adaptation of Coping Self-Efficacy Scale in Latvian. 11th European Conference on Psychological Assessment. 2011 Riga.. 